\title{
REVIEW
}

\section{Should we definitively abandon prophylaxis for patent ductus arteriosus in preterm new-borns?}

\author{
Vassilios Fanos, Michele Pusceddu, Angelica Dessì, Maria Antonietta Marcialis \\ Neonatal Intensive Care Unit, Puericulture Institute And Neonatal Section, AOU University of Cagliari, Italy.
}

Although the prophylactic administration of indomethacin in extremely low-birth weight infants reduces the frequency of patent ductus arteriosus and severe intraventricular hemorrhage, it does not appear to provide any long-term benefit in terms of survival without neurosensory and cognitive outcomes. Considering the increased drug-induced reduction in renal, intestinal, and cerebral blood flow, the use of prophylaxis cannot be routinely recommended in preterm neonates. However, a better understanding of the genetic background of each infant may allow for individualized prophylaxis using NSAIDs and metabolomics.

KEYWORDS: Ductus Arteriosus, Preterm Newborn, Prophilaxis, Indometacin, NSAIDs.

Fanos V, Pusceddu M, Dessi A, Marcialis MA. Should we definitively abandon prophylaxis for patent ductus arteriosus in preterm new-borns? Clinics. 2011;66(12):2141-2149

Received for publication on June 7, 2011; First review completed on July 5, 2011; Accepted for publication on August 12, 2011

E-mail: baire@unica.it

Tel.: +390706093403

\section{INTRODUCTION}

Botallo's duct is a blood vessel that connects the pulmonary artery to the aorta during fetal development, and our knowledge of the pathophysiology of this duct is increasing steadily. ${ }^{1}$

Clinically, 'patent DA' (ductus arteriosus) is often used synonymously with 'persistent $\mathrm{DA}^{\prime}$, and both are frequently abbreviated as 'PDA' even though they differ in morphology and therapeutic implications. ${ }^{2,3}$ The term 'patent DA' is an umbrella term that is used for all situations in which the DA is either physiologically or pathologically open. In this review, we will use the abbreviation ' $\mathrm{PDA}^{\prime}$ ' to refer to patent ductus arteriosus.

A patent ductus arteriosus (PDA) is a physiologic shunt in healthy full-term and preterm infants that tipically presents during the first three days of life. ${ }^{4}$

PDA in preterm infants may have clinical consequences depending on the degree of left-to-right shunting. The increase in pulmonary blood flow in premature infants may lead to pulmonary edema, loss of lung compliance, and deterioration of the respiratory status, which ultimately lead to chronic lung disease (CLD) and an increased morbidity and mortality. ${ }^{5}$

A shunting of blood between the aorta and pulmonary artery, which is favored by the postnatal decrease in pulmonary vascular resistance, ${ }^{6}$ causes the hemodynamic and clinical consequences of PDA. The shunt also modifies the distribution of blood to the lungs and other organs and may contribute to an increased risk of serious and

Copyright (c) 2011 CLINICS - This is an Open Access article distributed under the terms of the Creative Commons Attribution Non-Commercial License (http:// creativecommons.org/licenses/by-nc/3.0/) which permits unrestricted noncommercial use, distribution, and reproduction in any medium, provided the original work is properly cited.

No potential conflict of interest was reported. prolonged neonatal respiratory distress, intraventricular hemorrhage (IVH), necrotizing enterocolitis (NEC), bronchopulmonary dysplasia (BPD), and death. ${ }^{7,8}$

The incidence of PDA in full-term neonates has been estimated to be 57 per 100,000 live births, ${ }^{3}$ whereas persistence of the duct occurs in approximately one-third of premature neonates with a birth weight between 501 and 1,500 grams. $^{9}$

In neonates weighing less than $1,000 \mathrm{~g}$, it has been reported that $55 \%$ develop a symptomatic PDA requiring pharmacological treatment. ${ }^{10,11}$ The spontaneous closure of a PDA takes place between the second and sixth day of life in $34 \%$ of extremely low birth weight (ELBW) neonates ${ }^{12}$ and within the first year of life in the majority of very low birth weight (VLBW) neonates.

Postnatal ductal closure is regulated by exposure to oxygen and vasodilators. The ensuing vascular response, which is mediated by potassium channels, voltage-gated calcium channels, mitochondria-derived reactive oxygen species, and endothelin 1, depends on the gestational age. Platelets are recruited to the luminal surface of the DA during closure and are hypothesized to promote the thrombotic sealing of the constricted DA. ${ }^{13}$

It has been estimated that $60 \%$ to $70 \%$ of preterm infants less than 28 gestational weeks receive medical or surgical therapy for a PDA, usually with the intention to prevent respiratory decompensation, heart failure, IVH/brain injury, BPD, NEC, and death. ${ }^{14,15}$

The natural history of PDA in premature infants remains unknown, and its management is highly controversial. The following four strategies are most often used in the treatment of PDA: 1) symptomatic treatment when the duct is deemed hemodynamically relevant by clinical or ultrasonographic evaluation; ${ }^{16}$ 2) targeted treatment of ducts echocardiographically detected in the first 24 hours of life but before a significant left-right shunt has developed; ${ }^{17} 3$ ) 
conservative management with only ventilation adjustments and fluid restriction; 4) a prophylactic approach, which medically or surgically treats all neonates at risk for PDA in the first 24 hours of life. ${ }^{18}$

Despite numerous studies, some controversies regarding PDA prevention remains. The prophylactic use of indomethacin, whether the DA is patent or not, is the beststudied regimen. The timing of this approach is important (it is given very early, within the first 24 hours) because its effectiveness clearly decreases with increasing postnatal age; however, this treatment involves the risks associated with exposing infants to drugs that they might not need.

Importantly, prophylactic trials can examine the association between PDA and the incidence of IVH or pulmonary hemorrhage, which typically occurs within the first moments of life, whereas symptomatic trials cannot examine this relationship. Conversely, symptomatic trials can examine the relationship between PDA and NEC, which occurs later in postnatal life, whereas prophylactic trials would be unlikely to do so. ${ }^{19,20}$

In this paper, we will only address the prophylactic approach for PDA management.

\section{PROPHYLACTIC USE OF INDOMETHACIN}

Indomethacin is used prophylactically to close the PDA before hemodynamic distress occurs, which has been associated with an increased morbidity and mortality, without the need for screening or echocardiographic surveillance. This approach exposes a large number of neonates, in whom the duct would close spontaneously, to a pharmacologic treatment that is not without risk.

Intravenous indomethacin, a non-selective cyclooxygenase inhibitor, is the standard pharmacological treatment for PDA in preterm neonates and has a reported effectiveness of $66-80 \%$. $^{21-23}$

Since the 1980s, several risk-benefit studies have been conducted to evaluate the intravenous administration of indomethacin for prophylactic treatment of PDA. The first small, controlled, randomized trials suggested that early prophylaxis (i.e., within the first 24 hours) with indomethacin reduced the incidence of serious IVH.

Interestingly, a significant increase in the use of indomethacin prophylaxis occurred after the Ment et al. trial was published; however, a significant decrease in the use of indomethacin prophylaxis followed the TIPP trial. ${ }^{24}$

In 1994, Ment et al. ${ }^{25}$ was the first to publish a prospective, randomized, placebo-controlled trial to investigate whether low-dose indomethacin $(0.1 \mathrm{mg} / \mathrm{kg}$ intravenously at 6 to 12 postnatal hours and every 24 hours for two more doses) would lower the incidence and severity of IVH.

The authors enrolled 431 neonates with a birth weight of 600 to $1,250 \mathrm{~g}$ and no evidence of IVH at 6 to 11 hours of age. Serial cranial ultrasounds and echocardiograms were performed. Within the first five days, 25 (12\%) indomethacin-treated and $40(18 \%)$ placebo-treated neonates developed IVH $(p=0.03$, trend test). However, only one indomethacin-treated patient experienced grade $4 \mathrm{IVH}$ versus 10 placebo-treated neonates $(p=0.01)$.

In 2001, Schmidt ${ }^{26}$ published the results of another largescale, controlled, randomized trial, the Trial of Indomethacin Prophylaxis in Preterm (TIPP), that evaluated the long-term effects of indomethacin on motor, sensory and cognitive outcomes.
In this study, 1,202 ELBW infants (500-999 g) were randomly assigned to receive either indomethacin (0.1 mg per kilogram of body weight) or placebo intravenously once daily for three days soon after birth.

The primary outcomes investigated were death, cerebral palsy, cognitive delay, deafness, and blindness at a corrected age of 18 months. The secondary long-term outcomes were hydrocephalus necessitating placement of a shunt, seizure disorder, and microcephaly within the same time frame. Secondary short-term outcomes were PDA, pulmonary hemorrhage, chronic lung disease, ultrasonographic evidence of intracranial abnormalities, necrotizing enterocolitis, and retinopathy.

Of the 574 infants with primary outcome data who received indomethacin prophylaxis, 271 (47\%) died or survived with impairments, as compared with 261 of the 569 infants $(46 \%)$ assigned to placebo (odds ratio, 1.1; 95 percent confidence interval, 0.8 to $1.4 ; p=0.61$ ).

Indomethacin reduced the incidence of PDA ( $24 \%$ vs. $50 \%$ in the placebo group; odds ratio, $0.3 ; p<0.001)$ and severe PVH and IVH ( $9 \%$, vs. $13 \%$ in the placebo group; odds ratio, 0.6 ; $p=0.02)$. No other outcomes were altered by the prophylactic administration of indomethacin. However, indomethacin prophylaxis increased the need for supplemental oxygen from day 3 to at least day 7 of life. Indomethacin also decreased the urine volume during the first four days of life and reduced weight loss by the end of the first week.

These papers concluded that in ELBW infants, indomethacin prophylaxis does not improve the survival rate without neurosensory impairment at 18 months, despite the fact that it reduces the frequency of PDA (NNT 4) and severe PVH and IVH.

The reduction in IVH can be explained by the maturation of the cerebral vascular basement membrane, improvement in cerebrovascular self-regulation and anti-inflammatory effects. $^{27,28}$ More recent data detailing reduced germinal matrix hemorrhaging via inhibition of angiogenesis indirectly support this hypothesis. ${ }^{29}$

In a follow-up to the TIPP study, 999 ELBW were given indomethacin prophylaxis. The treatment did not prevent $\mathrm{BPD}$, although it reduced the frequency of PDA. ${ }^{30}$

The frequency of CLD was higher, which may be associated with the reduced weight loss, the greater need for oxygen and perhaps the increase in extracellular liquid at the pulmonary level.

Reducing the frequency of PDA may be important for those children requiring surgical closure, although twenty prophylactic treatments with indomethacin are required to avoid surgical treatment.

In another follow-up to the TIPP study that was continued up to 18 months of life, prophylactic indomethacin reduced the rate of early serious pulmonary hemorrhage because of its effects on PDA. However, prophylactic indomethacin was less effective in preventing serious pulmonary hemorrhages that occur after the first week of life. ${ }^{31}$ Currently, the main limitations of the TIPP trial are methodological concerns, such as the use of composite outcomes and a lack of statistical power.

Another important study was published by Vohr. ${ }^{32}$ Their cohort consisted of 328 VLBW (birth weight of 600-1,250 g) infants who were enrolled in a low-dose, prophylactic indomethacin prevention trial and IVH negative at six postnatal hours. 
The cohort was divided into the following four subgroups for analysis: indomethacin plus IVH, indomethacin without IVH, saline plus IVH, and saline without IVH. The children were evaluated prospectively at eight years old. Children in both IVH groups had more cerebral palsy and hearing impairment as well as lower daily living skills scores, IQ scores, and vocabulary, reading and mathematics achievement test scores. Additionally, these children had greater educational resource needs. Logistic regression analyses showed that grade 3 to $4 \mathrm{IVH}$, periventricular leukomalacia and/or ventriculomegaly, male gender, maternal education, and the language spoken at home contributed to the outcomes. The authors concluded that although biological factors contribute significantly to school-related outcomes in VLBW survivors, social and environmental factors are also important contributors. Importantly, no effects of indomethacin or gestational age were identified in this study.

Cordero et al. ${ }^{33}$ compared the clinical responses of ELBW infants to indomethacin prophylaxis to that of other infants who were managed with indomethacin or surgical treatment only after a symptomatic PDA was detected. The study was a retrospective cohort investigation of 167 ELBW infants who received indomethacin prophylaxis (study) and 167 ELBW infants treated after detecting a symptomatic PDA (control) who were matched by year of birth (1999 to 2006), birth weight, gestational age (GA) and gender. Indomethacin prophylaxis did not show any advantages over early treatment for managing a symptomatic PDA in ELBW infants. The incidence of IVH was the same in the newborns receiving indomethacin prophylaxis and those in the control group.

The use of indomethacin to prevent PDA has been demonstrated to reduce the incidence of a symptomatic duct, the need for surgical closure and the occurrence of pulmonary hemorrhage. ${ }^{34,35}$ However, whether this reduction is significant has been controversial. ${ }^{36}$

A recent meta-analysis of 19 studies in Cochrane (involving 2,872 preterm infants) that also included the trials by Ment and Schmidt discussed above, confirmed that prophylactic indomethacin has short-term benefits for preterm infants, including a reduction in the incidence of symptomatic PDA, the need for surgical PDA ligation, and severe IVH. However, there was no evidence of its effect on mortality or neurodevelopment. ${ }^{5}$

Four neonates must be treated to close one DA (i.e., four is the number needed to treat) and twenty to avoid IVH. The same number 20 is needed to avoid surgical closure and pulmonary hemorrhage, and 25 are required to avoid a periventricular leukomalacia. Unfortunately, there was no effect on mortality or the long-term neurological outcomes.

However, prophylactic indomethacin does not reduce the incidence of pneumothorax, the duration of ventilation, the duration of oxygen therapy or the incidence of CLD (at 28 days or 36 weeks). CLD, brain injury and ROP were predictive factors of late death or neurosensory impairment in the follow-up to the TIPP study. ${ }^{37}$

There are recent data on the long-term alterations that are observed at school age in preterm children who were treated with indomethacin or saline. ${ }^{38,39}$ At 12 years of age, those children who had received indomethacin prophylaxis had an increased amount of gray matter in the left inferior parietal lobe, which is responsible for phonologic processes. Males had better phonological scores than saline-treated males. ${ }^{40}$ Again, newborns given indomethacin prophylaxis had greater parenchyma in the left lingual lobe at 8 years, but there was no effect on reading. Finally, newborns given indomethacin prophylaxis at birth had better connectivity between specific areas of the two hemispheres (from the right BA 40 and BA 44-45 to the left BA 22). However, indomethacin did not affect the intellectual function of children who were born preterm. ${ }^{41,42}$

The only major side effect of indomethacin reported in the 2010 Cochrane review was the increased incidence of oliguria, but it was not associated with any documented kidney damage. In the same review, no differences in the incidence of NEC or excessive bleeding were demonstrated. However, there were several side effects following the use of indomethacin demonstrated that raise serious concerns, including a reduction in cerebral blood flow, ${ }^{27,43,44}$ the volume of blood delivered to the brain and the release of brain tissue oxygen; ${ }^{45}$ oliguria and transitory kidney insufficiency; ${ }^{46,21-23}$ necrotizing enterocolitis; isolated intestinal perforation; and gastrointestinal hemorrhage. ${ }^{21,47}$

It is important to note that administering furosemide before each indomethacin dose resulted in a significant increase in the serum creatinine level and hyponatremia without increasing urine output. ${ }^{48}$

Although most of the included studies were high quality, the drug dosage varied from one study to another, and the patient population was not homogeneous in terms of weight or gestational age. Some studies included case histories that occurred before the use of prenatal steroids or endotracheal surfactants was widespread. Furthermore, in each study, some patients in the control group were contaminated (crossed-over) because they had received indomethacin outside the limits of the study. ${ }^{5}$

Interestingly, some authors found that the timing of the first dose of indomethacin was significantly associated with the closure rate and that early administration reduced the need for surgical ligation. Up to $85.2 \%$ of DAs closed if the first dose of indomethacin was administered within 24 hours of birth; however, this rate decreased to $48.1 \%$ when treatment was started 72 hours or later after birth. The corresponding rates for surgical ligation were $3.7 \%$ and $25.9 \%$, respectively. ${ }^{49}$

In conclusion, various clinical trials have demonstrated the effectiveness of indomethacin prophylaxis in closing Botallo's duct, but none have answered the fundamental question of whether the prophylactic closure improved the outcome. Prophylaxis does not appear to influence the development of CLD, septicemia, ROP or mortality. Although prophylaxis is associated with a reduction in serious IVHs, an important predictor of long-term neurological outcome, why prophylaxis does not influence longterm neuromotor outcomes is not known.

In an observational study, a longer duration of indomethacin exposure was associated with less white matter injury in infants delivered before 28 weeks of gestation. ${ }^{50}$

In a study by Madan, ${ }^{51} 29 \%$ of 881 ELBW patients received indomethacin prophylaxis within the first 24 hours of life. The authors found that prophylaxis had no effect on outcomes except for a borderline increase in NEC frequency in those subjects who received prophylaxis and indomethacin therapy. In a recent study, the indomethacin prophylaxis was directed by echocardiography. ${ }^{52}$

Recently, the prophylactic administration of indomethacin in extremely premature infants (i.e., those born between 23 and 24 weeks of gestation) decreased the incidence of symptomatic PDA without increasing the incidence of adverse effects. ${ }^{53}$ 
In a study conducted in Asia, the incidence of IVH and other episodes of bleeding were significantly higher than in the controls, and the study was stopped early. ${ }^{54}$

Lower platelet counts have been associated with a higher failure rate of indomethacin-induced PDA closure in human newborns, which is pertinent to clinical practice. ${ }^{55}$

Additionally, administering cortisol to immature fetal lambs in utero results in a ductus that responds to oxygen and prostaglandin inhibition similar to that of a mature fetus, which explains the decreased incidence of PDA in preterm humans who are born to mothers who received antenatal corticosteroids. ${ }^{56,14}$

Two commentary articles in the Journal of Pediatrics emphasized that the consequences of treatment for PDA, including the pharmacological side effects and surgery, might be more harmful to the infant than the PDA itself. ${ }^{57,19}$

Moreover, there has been concern about the use of NSAIDs and their long-term renal effects in ELBW infants. In fact, ELBW infants treated with NSAIDs and aminoglycosides have been found to have a renal volume less than the 10 th percentile at 7 years of age in $40 \%$ of cases, which is associated with $\alpha 1$ microglobinuria. ${ }^{58}$

Recently, Evans has adopted a new, targeted refinement of prophylactic indomethacin, which consists of giving indomethacin for early post-natal duct constriction assessed echocardiographically. The author has also cited the ongoing Australian DETECT trial, which includes infants born before 29 weeks of gestation who, before being treated (within the first 12 hours and, ideally, in the first 6 hours), were examined using an echocardiogram to assess the duct diameter. In this trial, preterm infants with well-constricted ducts were not treated. ${ }^{59}$

\section{PROPHYLACTIC USE OF IBUPROFEN}

Preliminary experimental and clinical studies ${ }^{60,61}$ have shown that ibuprofen, another cyclooxygenase inhibitor, effectively closes the PDA without reducing the blood flow to the brain ${ }^{45,62}$ or influencing circulation in the intestines ${ }^{63}$ or kidneys. ${ }^{64}$

Van Overmeire performed a randomized, placebo-controlled trial to determine whether ibuprofen could reduce class III and IV IVH in patients with a gestational age of 24 to 30 weeks. This study showed that a significant reduction in the incidence of PDA $(16 \%)$ was associated with a lack of differences in the primary outcome of serious IVH (ibuprofen does not reduce the frequency of IVH). Additionally, a lack of differences was not seen in any secondary outcomes, including mortality, PVL, combined CLD outcomes or death at 36 weeks. In those receiving prophylaxis, there was a significant increase in oliguria or an increase in creatinine when compared with the group that did not receive prophylactic treatment. ${ }^{65}$ A recent meta-analysis ${ }^{66}$ of prophylactic ibuprofen for PDA showed a reduced incidence of PDA, a reduced need for symptomatic treatment with cyclooxygenase inhibitors and a reduced need for surgical ligation. No advantage in the short-term outcomes was demonstrated; no statistically significant difference in the mortality or the incidence of BPD, NEC, gastrointestinal hemorrhage, intestinal perforation, or ROP was demonstrated between the ibuprofen-treated and placebo groups. There was a statistically significant negative effect on kidney function. In the control group, the PDA closed spontaneously by day three in $58 \%$ of the neonates.
Based on the current clinical data, there are no benefits and possibly some harm with both the early use of ibuprofen as either prophylaxis or treatment in the first 24 hours of life ${ }^{17,66}$ (e.g., pulmonary hypertension) ${ }^{67-69}$ and prolonged courses of indomethacin (e.g., NEC). ${ }^{16}$

Ibuprofen therapy for PDA closure in preterm baboon neonates was not associated with any increased risk of neuropathology or alterations in brain growth and development. $^{70}$

Treatment with ibuprofen is safer than indomethacin because there is a decreased risk of renal failure, thrombocytopenia, and hyponatremia with ibuprofen. ${ }^{71}$

Renal safety should be emphasized because this is a major consideration in choosing ibuprofen instead of indomethacin for early treatment.

There is sufficient evidence to suggest that ibuprofen, at the currently proposed dosing regimen, has an efficacy similar to that of indomethacin but is better tolerated by the neonatal kidney when used to treat established PDA. ${ }^{72}$

This finding has been also observed in animals. In suckling rats, indomethacin suppressed PGE2 and COX-2 expression and increased PGF2 expression, whereas ibuprofen increased COX-2 and angiotensin II expression. Although both NSAIDs suppressed 6-ketoPGF1 and TxB2 expression in suckling rats, the effect was sustained in weanling rats with indomethacin. Thus, indomethacin exhibits more potent suppressive effects on the expression of renal COX-2 and vasodilator prostanoids, which are important regulators of renal development and function. These long-term, sustained effects may partly explain why indomethacin has more severe adverse renal effects than ibuprofen when administered early in postnatal life. ${ }^{73}$

Based on our personal experience, ${ }^{75-80}$ although ibuprofen is less nephrotoxic than indomethacin, it may still have adverse renal effects, even when administrated orally. ${ }^{73}$ These negative renal effects are only partially compensated by the protection against oxidative stress. ${ }^{81}$

A recent paper by Vieux has confirmed our findings. ${ }^{82}$ They found that ibuprofen-induced oligo-anuria is not associated with a change in AQP2 activity and that ibuprofen does not affect AQP2 activity during the first month of life in very preterm neonates. ${ }^{83}$ This is in apparent contrast with the findings from a long-term renal follow-up of premature infants with and without perinatal indomethacin exposure. In an older study, ${ }^{84}$ perinatal indomethacin did not affect longterm renal growth, morphology or function in children born before completing 33 weeks of gestation. However, in this study, the duration of umbilical artery catheterization, furosemide treatment and assisted ventilation were associated with the later renal structural and functional anomalies.

Similar results have been obtained by other investigators. ${ }^{85}$

Therefore, prophylaxis unnecessarily exposes infants to a drug with worrisome renal side effects without conferring any significant short-term benefits. Prophylactic ibuprofen treatment is not recommended.

Ibuprofen prophylaxis is associated with a higher incidence of CLD. The conclusions to date do not support the use of ibuprofen in PDA prophylaxis. ${ }^{17,66}$

\section{PROPHYLACTIC SURGICAL LIGATION}

The results of only one study that enrolled 84 ELBW infants have been reported. The prophylactic group underwent ductal ligation within 24 hours of life following a pre-specified 
protocol, whereas the control group received standard care without indomethacin. ${ }^{86}$

Whereas prophylactic surgical ligation of the PDA did not decrease mortality or BPD in ELBW infants, the incidence of stage II and III NEC was significantly reduced. Based on the current evidence, high rate of spontaneous closure, availability of effective safe medical therapies, and potential short- and long-term complications of surgical ligation, the use of prophylactic surgical ligation is not indicated. ${ }^{87}$

Recently, a re-examination of this controlled trial by the authors found that prophylactic ligation significantly increased the incidence of BPD (defined as a need for supplemental oxygen at 36 weeks postmenstrual age) and the incidence of mechanical ventilation at 36 weeks. These findings suggest that although surgical prophylactic ductus ligation eliminates the PDA, it may contribute to the problem it is trying to prevent. Experimental studies have been initiated to answer this question. ${ }^{88}$

Recently, in a study examining premature baboons versus baboons with a persistent PDA, ibuprofen treatment had no effect on the expression of genes that regulate pulmonary inflammation but did increase the expression of alpha$\mathrm{ENaC}$, the transepithelial sodium channel that is critical for alveolar water clearance. Although ligation eliminates the PDA, it does not improve pulmonary mechanics or increase the alveolar surface area. In contrast with no intervention, PDA ligation resulted in a significant increase in the expression of genes associated with pulmonary inflammation (e.g., COX-2, TNF-alpha, and CD14) and a significant decrease in alpha-ENaC expression. The authors speculated that these changes may decrease the rate of alveolar fluid clearance and contribute to the lack of improvement in pulmonary mechanics following PDA ligation. ${ }^{89}$

The last report from the TIPP study reported that surgical closure of a PDA reduced mortality to an almost significant extent. However, neurosensory impairment was also significantly increased by 18 months of age, as were retinopathy of prematurity and BPD. ${ }^{90}$ These findings are also supported by others. ${ }^{91}$

Furthermore, it has been shown that there is a general association between any surgery in the neonatal period and neurosensory impairment at five years of age, indicating that surgery and anesthesia might be independent risk factors in VLBW infants. ${ }^{92}$

Bratlid recently confirmed that the surgical closure of a patent DA in a small premature infant is associated with neurosensory impairment. ${ }^{93}$

The following adverse events have been reported to be associated with the surgical closure of PDA: recurrent laryngeal nerve damage, chylothorax (thoracic duct injury), pneumothorax, a period of left ventricular dysfunction immediately after ligation, and the development of scoliosis. $^{94-98}$

Moreover, PDA ligation is sometimes associated with impaired left ventricular systolic performance, which is most likely attributable to altered loading conditions. Neonates weighing $1,000 \mathrm{~g}$ or less are at an increased risk of impaired left ventricular systolic performance, which is probably due to maturational differences. ${ }^{99}$

Finally, it has very recently been confirmed that ligation in preterm neonates has a considerable risk. Total mortality in this vulnerable group of patients was $15 \%$. Moreover, severe complications and post-operative morbidity have been reported. ${ }^{100}$
In conclusion, the current evidence does not support the use of prophylactic surgical ligation of DAs in preterm infants. ${ }^{101}$

However, it is vital for clinicians to understand the fluid and cardiovascular changes that occur at birth and during PDA management to gain a better appreciation of the pathologic processes that may influence the clinical course of an affected infant. ${ }^{102}$

\section{FUTURE DIRECTIONS: THE IMPORTANCE OF GENETIC FACTORS}

It has been hypothesized that genetic factors play a significant role in the pathophysiology of PDA. ${ }^{103}$

A retrospective study (1991-2006) from two centers was performed using zygosity data from premature twins born at 36 weeks of gestational age and surviving beyond 36 weeks of postmenstrual age.

Data from 333 dizygotic twin pairs and 99 monozygotic twin pairs from two centers (Yale University and the University of Connecticut) were obtained. The conclusion was that preterm PDA is highly familial. ${ }^{103,104}$ While this is the first study that formally isolated and quantified the overall heritability, other studies have addressed the problem.

In a candidate gene study of $141 \mathrm{LBW}$ newborns, Derzbach et al. ${ }^{105}$ reported that boys with the " $p$ " allele of the estrogen receptor gene PvuII $\mathrm{pP}$ polymorphism were at a lower risk for PDA but with a wide CI (OR: 0.24, 95\% CI: 0.05-0.97).

In another candidate gene study of 153 LBW newborns, Bokodi et al. ${ }^{106}$ showed that carriers of the interferon gamma (+874) $\mathrm{T}$ allele were protected against PDA (OR: $0.43,95 \%$ CI: $0.19-0.97)$ with a similarly wide CI.

Because approximately $30 \%$ of infants with PDA do not respond to pharmacologic treatments for closure, some authors have investigated whether single nucleotide polymorphisms (SNPs) in genes that regulate smooth muscle contraction, xenobiotic detoxification, inflammation or other processes are markers for the persistent patency of the DA. Initially, 377 SNPs from 130 genes of interest were evaluated in DNA samples collected from 204 infants with a gestational age of less than 32 weeks.

SNPs in the AP-2 beta (TFAP2B) and TNF receptorassociated factor 1 (TRAF1) genes remained significant, both with $p$-values of 0.005 . These data support a genetic contribution to the risk of PDA in preterm infants. ${ }^{107}$

Genetic polymorphisms in the cytochrome P450 (CYP) family of enzymes can contribute to the pharmacokinetic (PK) variability of drugs. PK variability is observed as a bimodal distribution of extensive metabolizers (EMs) and poor metabolizers (PMs). PK variability may also exist between individuals genotyped as homozygous EMs and heterozygous EMs. This can have implications for drug dosing and the drug response (e.g., the risk of therapeutic failure or drug toxicity), especially for NSAIDs. ${ }^{108}$

However, CYP2C8 and 2C9 polymorphisms do not appear to be involved in the response of preterm infants to ibuprofen therapy for PDA and cannot be used to optimize the ductal closure rate by modulating the ibuprofen-dosing strategy. ${ }^{109}$ In contrast, this study reported the role of ethnicity in the interindividual variability of the response to ibuprofen and subsequent PDA closure in preterm infants. Interethnic differences in the neonatal PDA clinical course should be further explored and correlated to ibuprofen pharmacokinetics. ${ }^{109}$ Additionally, recent studies have reported that three 
Table 1 - Ten reasons to definitively abandon PDA prophylaxis.

1) The DA closes spontaneously in $60 \%$ of patients.

2) Surgical prophylaxis cannot be recommended because it significantly increases the incidence of BPD.

3) Ibuprofen prophylaxis cannot be recommended, as it does not prevent IVH.

4) Routine indomethacin prophylaxis cannot be recommended for the prevention of long-term morbidities and mortality, especially in centers where severe IVH is comparable to the national average and surgical complications are minimal.

5) In Europe, only 5\% of neonatologists use prophylaxis (data from a recent review); in the US, $23 \%$ use it.

6) The commonly used NSAIDs are associated with short-term (and probably) long-term side effects.

7) Indomethacin prophylaxis unethically exposes newborns who will never have a persistent patent DA to the side effects of drugs.

8) Differences in patient genetics, drug response, ethnicity, gender, history, and biohumoral profiles and procedures in single centers make it extremely difficult to predict the efficacy and safety of prophylaxis.

9) Epigenetic influences, which are not completely understood, may further complicate the scenario.

10) New technologies, such as pharmacogenomics and pharmacometabolomics, will allow the practice of personalized neonatal medicine.

independent risk factors (immature gestation, the absence of antenatal glucocorticoid exposure, and the presence of the rs2817399(A) allele of the gene, TFAP2B) are associated with DAs that fail to close with prostaglandin inhibition. Furthermore, these risk factors affected a common set of genes that increase the risk of persistent PDA after birth. In a study examining the ductus in term, preterm, and glucocorticoid-treated preterm baboon fetuses, it was found that both immature birth and the absence of antenatal glucocorticoids decreased the RNA expression of the calcium- and potassiumchannel genes involved in oxygen-induced constriction and phosphodiesterase genes, which modulate cAMP/cGMP signaling. Furthermore, in a study in which ductus obtained from second trimester human pregnancies were genotyped for TFAP2B polymorphisms, when present, the rs2817399(A) allele was also associated with the decreased expression of calcium- and potassium-channel genes. In contrast, alleles of two other TFAP2B polymorphisms, rs $2817419(\mathrm{G})$ and rs2635727(T), were not correlated with the incidence of PDA after birth and had no effect on RNA expression. Three calcium- and potassium-channel genes (CACNA1G/ alpha1G, CACNB 2/CaL-beta2, and KCNA2/Kv1.2) were similarly affected by each of the risk factors associated with PDA. The authors speculated that these channels may play a significant role in closing the preterm ductus following prostaglandin inhibition and may be potential targets for future pharmacologic manipulations. ${ }^{110}$

Therefore, knowing the genes responsible for maintaining the balance between patency and closure and the related epigenetic factors is an important step toward developing pharmacogenetic strategies tailored to individual genomes. A better understanding of the genetic background of this developmental process can help develop new strategies to manipulate the DA in premature infants, neonates with duct-dependent cardiac anomalies, and patients with syndromic and non-syndromic PDA. ${ }^{104}$ The practical message is that, if these data are true, we must individualize NSAID treatment and prophylaxis. ${ }^{112}$ Metabolomics may provide the answer to this question. ${ }^{112,113}$ In fact, a metabolic signature for PDA in preterm infants has been identified using an NMR-based metabolomic analysis of urine. ${ }^{113}$ By collecting the first urine at birth, it is possible to anticipate the persistence of PDA at day 4.

\section{CONCLUSIONS}

There has been much debate in recent years as to when a PDA is pathologic and when closure is indicated. There is a pressing need to better understand the benefits and risks of all PDA treatments. ${ }^{114-122}$
Currently, it is unclear whether and when a conservative, pharmacologic or surgical approach for PDA closure may be advantageous, ${ }^{13}$ and this is also the opinion of the authors. ${ }^{118,119}$

Based on the current literature, we can offer some suggestions regarding prophylaxis.

Al Faleh, who supports the prophylactic use of indomethacin, has recently hypothesized that the results of the TIPP study were influenced by fluid overload and pulmonary edema. In his opinion, fluid restriction might decrease the rate of BPD in ELBW infants who receive indomethacin prophylaxis. ${ }^{120}$

Prophylaxis with ibuprofen cannot be recommended, as it does not prevent IVH; it is important to avoid ibuprofen in infants in whom the DA may spontaneously close. Routine prophylaxis with indomethacin cannot be recommended for the prevention of long-term morbidities and mortality, especially in centers where severe IVH is comparable to the national average and surgical complications are minimal. ${ }^{120}$

Table 1 presents ten reasons for definitively abandoning PDA prophylaxis.

In conclusion, because they expose a significant number of preterm infants who will never develop PDA (40-60\%) to potential severe, drug-related complications, all types of PDA prophylaxis, including indomethacin, cannot be considered a 'standard of care' until their long-term efficacy is proven in clinical trials.

\section{AUTHOR CONTRIBUTIONS}

Fanos $\mathrm{V}$ had the original idea and wrote the manuscript together with Marcialis MA. Pusceddu M and Dessi A collected all the references, compared all the papers, and had minor participation in the writing of the manuscript.

\section{REFERENCES}

1. Gournay V. The ductus arteriosus: Physiology, regulation, and functional and congenital anomalies. Arch Cardiovasc Dis, 2010, doi: 10.1016/j.acvd.2010.06.006.

2. Gittenberger-de Groot AC. Persistent ductus arteriosus: most probably a primary congenital malformation. Br Heart J. 1977;39:610-8, doi: 10. 1136/hrt.39.6.610

3. Chuaqui B, Piwonka G, Farrú O. The wall in persistent ductus arteriosus (in German). Virchows Arch A Pathol Anat Histol. 1977;372:315-24, doi: 10.1007/BF00432406.

4. Skinner J. Diagnosis of patent ductus arteriosus. Semin Neonatol. 2001;6:49-61, doi: 10.1053/siny.2000.0037.

5. Fowlie PW, Davis PG, McGuire W. Prophylactic intravenous indomethacin for preventing mortality and morbidity in preterm infants. Cochrane Database of Systematic Reviews. 2010;7:CD000174, doi: 10.1002/14651858.CD000174.pub2

6. Evans N, Kluckow M. Early determinants of right and left ventricular output in ventilated preterm infants. Archives of Disease in Childhood. Fetal and Neonatal Edition. 1996;74:F88-94, doi: 10.1136/fn.74.2.F88. 
7. Brown ER. Increased risk of bronchopulmonary dysplasia in infants with patent ductus arteriosus. J Pediatr. 1979;95:865-6, doi: 10.1016/ S0022-3476(79)80454-0.

8. Lipman B, Server GA, Brazy JE. Abnormal cerebral haemodynamics in preterm infants with patent ductus arteriosus. Pediatrics. 1982;69:77881.

9. Investigators of the Vermont-Oxford Trials Network Database Project. The Vermont- Oxford Trials Network: very low birth weight outcomes for 1990. Pediatrics. 1993;91:540-5.

10. Koch J, Hensley G, Roy L, Brown S, Ramaciotti C, Rosenfeld CR. Prevalence of spontaneous closure of the ductus arteriosus in neonates at a birth weight of 1000 grams or less. Pediatrics. 2006;117:1113-21, doi: 10.1542 /peds.2005-1528.

11. Richards J, Johnson A, Fox G, Campbell M. A second course of ibuprofen is effective in the closure of a clinically significant PDA in ELBW infants. Pediatrics. 2009;124:e287-e293, doi: 10.1542/peds.20082232.

12. Herrman K, Bose C, Lewis K, Laughon M. Spontaneous closure of the patent ductus arteriosus in very low birth weight infants following discharge from the neonatal unit. Arch Dis Child Fetal Neonatal Ed. 2009;94:F48-F50

13. Hamrick SE, Hansmann G. Patent ductus arteriosus of the preterm infant. Pediatrics. 2010;125:1020-30, doi: 10.1542/peds.2009-3506.

14. Clyman RI. Ibuprofen and patent ductus arteriosus. N Engl J Med. 2000;343:728-30, doi: 10.1056/NEJM200009073431009.

15. Knight DB. The treatment of patent ductus arteriosus in preterm infants. A review and overview of randomized trials. Seminars in Neonatology. 2001;6:63-73.

16. Herrera C, Holberton J, Davis P. Prolonged versus short course of indomethacin for the treatment of patent ductus arteriosus in preterm infants. Cochrane Database of Systematic Reviews. 2007;2:CD003480, doi: 10.1002/14651858.CD003480.pub3

17. Ohlsson A, Walia R, Shah S. Ibuprofen for the treatment of patent ductus arteriosus in preterm and/or low birth weight infants. Cochrane Database of Systematic Reviews. 2010;4:CD003481, doi: 10.1002/ 14651858.CD003481.pub4

18. Golombek SG, Sola A, Baquero H, Borbonet D, Cabañas F, Fajardo C, et al. Primer Grupo de Consenso Clínico SIBEN. [First SIBEN clinical consensus: diagnostic and therapeutic approach to patent ductus arteriosus in premature newborns]. An Pediatr (Barc). 2008;69:454-81, doi: $10.1157 / 13128002$

19. Clyman RI, Chorne N. Patent ductus arteriosus: evidence for and against treatment. J Pediatr. 2007;150:216-9, doi: 10.1016/j.jpeds.2006. 12.048

20. Evans N. Patent ductus arteriosus and effects of low oxygen saturation limits. J Perinatol. 2009;29:529-30, doi: 10.1038/jp.2009.63.

21. Gersony WM, Peckham GJ, Ellison RC, Miettinen OS, Nadas AS. Effects of Indomethacin in premature infants with patent ductus arteriosus: results of a national collaborative study. Journal of Pediatrics. 1983;102:895-906, doi: 10.1016/S0022-3476(83)80022-5.

22. Van Overmeire B, Smets K, Lecoutere D, Van De Broek H,Weyler J, De Groote K, et al. A comparison of ibuprofen and indomethacin for closure of patent ductus arteriosus. New England Journal of Medicine. 2000;334:674-81, doi: 10.1056/NEJM200009073431001.

23. Lago P, Bettiol T, Salvadori S, Pitassi I, Vianello A, Chiandetti L, et al. Safety and efficacy of ibuprofen versus indomethacin in preterm infants treated for patent ductus arteriosus: a randomised controlled trial. European Journal of Pediatrics. 2002;161:202-7, doi: 10.1007/s00431002-0915-y.

24. Clyman RI, Saha S, Jobe A, Oh W. Indomethacin prophylaxis for preterm infants: the impact of 2 multicentered randomized controlled trials on clinical practice. J Pediatr. 2007;150:46-50.e2, doi: 10.1016/j. jpeds.2006.09.001.

25. Ment LR, Oh W, Ehrenkranz RA, Philip AG, Vohr B, Allan W, et al. Low-dose indomethacin and prevention of intraventricular hemorrhage: a multicenter randomized trial. Pediatrics. 1994;93:543-50.

26. Schmidt B, Davis P, Moddemann D, Ohlsson A, Roberts R, Saigal S, et al. Long-term effects of indomethacin prophylaxis in extremely low-birthweight infants. NEJM. 2001;344:1966-72, doi: 10.1056/NEJM20010628 3442602.

27. Edwards AD, Wyatt JS, Richardson C, Potter A, Cope M, Delply DT, et al. Effects of indomethacin on cerebral hemodynamics in very preterm infants. Lancet. 1990;335:1491-5, doi: 10.1016/01406736(90)93030-S.

28. Ment LR, Stewart WB, Ardito TA, Huang E, Madri JA. Indomethacin promotes germinal matrix microvessel maturation in the newborn beagle pup. Stroke. 1992;23:1132-7, doi: 10.1161/01.STR.23.8.1132.

29. Ballabh P, Xu H, Hu F, Braun A, Smith K, Rivera A, et al. Angiogenic inhibition reduces germinal matrix hemorrhage. Nat Med. 2007;13:47785, doi: $10.1038 / \mathrm{nm} 1558$

30. Schmidt B, Roberts RS, Fanaroff A, Davis P, Kirpalani HM, Nwaesei C, et al. TIPP Investigators. Indomethacin prophylaxis, patent ductus arteriosus, and the risk of bronchopulmonary dysplasia: further analyses from the Trial of Indomethacin Prophylaxis in Preterms (TIPP). J Pediatr. 2006;148:730-4, doi: 10.1016/j.jpeds.2006.01.047.

31. Alfaleh K, Smyth JA, Roberts RS, Solimano A, Asztalos EV, Schmidt B. Prevention and 18-month outcomes of serious pulmonary hemorrhage in extremely low birth weight infants: results from the trial of indomethacin prophylaxis in preterms. Trial of Indomethacin Prophylaxis in Preterms Investigators. Pediatrics. 2008;121:e233-8, doi: 10.1542/peds.2007-0028

32. Vohr BR, Allan WC, Westerveld M, Schneider KC, Katz KH, Makuch $\mathrm{RW}$, et al. School-age outcomes of very low birth weight infants in the indomethacin intraventricular hemorrhage prevention trial. Pediatrics. 2003;111:e340-6, doi: 10.1542/peds.111.4.e340.

33. Cordero L, Nankervis CA, Delooze D, Giannone PJ. Indomethacin prophylaxis or expectant treatment of patent ductus arteriosus in extremely low birth weight infants? J Perinatol. 2007;27:158-63, doi: 10 . 1038/sj.jp.7211659.

34. Couser RJ, Ferrara TB, Wright GB, Cabalka AK, Schilling CG, Hoekstra $\mathrm{RE}$, et al. Prophylactic Indomethacin therapy in the first twenty four hours of life for the prevention of patent ductus arteriosus in preterm infants treated prophylactically with surfactant in the delivery room. Journal of Pediatrics. 1996;128:631-7, doi: 10.1016/S0022-3476(96)80127-

35. Domanico RS, Waldman JD, Lester LA, McPhillips HA, Catrambone JE Covert RF. Prophylactic indomethacin reduces the incidence of pulmonary hemorrhage and patent ductus arteriosus in surfactant treated $<1250$ g. Pediatric Research. 1994;35:331A.

36. Knight DB, Laughon MM. Evidence for active closure of patent ductus arteriosus in very preterm infents. J Pediatrics. 2008;152:446-7, doi: 10 1016/j.jpeds.2007.10.016.

37. Schmidt B, Asztalos EV, Roberts RS, Robertson CM, Sauve RS, Whitfield MF. Trial of Indomethacin Prophylaxis in Preterms (TIPP) Investigators. Impact of bronchopulmonary dysplasia, brain injury, and severe retinopathy on the outcome of extremely low-birth-weight infants at 18 months: results from the trial of indomethacin prophylaxis in preterms. JAMA. 2003;289:1124-9, doi: 10.1001/jama.289.9.1124.

38. Gozzo Y, Vohr B, Lacadie C, Hampson M, Katz KH, Maller-Kesselman $\mathrm{J}$, et al. Alterations in neural connectivity in preterm children at school age. Neuroimage. 2009;48:458-63, doi: 10.1016/j.neuroimage.2009.06. 046 .

39. Mullen KM, Vohr BR, Katz KH, Schneider KC, Lacadie C, Hampson M et al. Preterm birth results in alterations in neural connectivity at age 16 years. Neuroimage. 2010;54:2563-70, doi: 10.1016/j.neuroimage.2010.11. 019.

40. Myers EH, Hampson M, Vohr B, Lacadie C, Frost SJ, Pugh KR, et al. Functional connectivity to a right hemisphere language center in prematurely born adolescents. Neuroimage. 2010;51:1445-52, doi: 10. 1016/j.neuroimage.2010.03.049.

41. Luu TM, Ment LR, Schneider KC, Katz KH, Allan WC, Vohr BR. Lasting effects of preterm birth and neonatal brain hemorrhage at 12 years of age. Pediatrics. 2009;123:1037-44, doi: 10.1542/peds.2008-1162.

42. Luu TM, Vohr BR, Schneider KC, Katz KH, Tucker R, Allan WC, et al Trajectories of receptive language development from 3 to 12 years of age for very preterm children. Pediatrics. 2009;124:333-41, doi: 10.1542/ peds.2008-2587

43. Van Bel F, Vande Borm, Stijnen T, Baan J, Ruys JH. Cerebral blood flow velocity changes in preterm infants after a single dose of indomethacin duration of its effect. Pediatrics. 1989;84:802-7.

44. Ohlsson A, Bottu J, Govan J, Ryan ML, Fong K, Myhr T. The effect of indomethacin on cerebral blood flow velocities in very low birth weight neonates with patent ductus arteriosus. Developmental Pharmacology and Therapeutics 1993;20:100-6.

45. Patel J, Roberts I, Azzopardi D, Hamilton P, Edwards AD. Randomised double blind controlled trial comparing the effects of ibuprofen with indomethacin on cerebral hemodynamics in preterm infants with paten ductus arteriosus. Ped Res. 2000;47:36-42, doi: 10.1203/00006450200001000-00009.

46. Betkerur MV, Yeh TF, Miller K, Glasser RJ, Pildes RS. Indomethacin and its effect on renal function and urinary kallikrein excretion in premature infants with patent ductus arteriosus. Pediatrics. 1981;68:99-102.

47. Grosfeld JL, Chaedt M,Molinari F. Increased risk of necrotizing enterocolitis in premature infants with patent ductus arteriosus treated with indomethacin. Annals of Surgery. 1996;224:350-7, doi: 10.1097/ 00000658-199609000-00011.

48. Andriessen P, Struis NC, Niemarkt H, Oetomo SB, Tanke RB, Van Overmeire B. Furosemide in preterm infants treated with indomethacin for patent ductus arteriosus. Acta Paediatr. 2009;98:797-803, doi: 10. $1111 / j .1651-2227.2009 .01224 . x$

49. Yang CZ, Lee J. Factors affecting successful closure of hemodynamically significant patent ductus arteriosus with indomethacin in extremely low birth weight infants. World J Pediatr. 2008;4:91-6, doi: 10.1007/ s12519-008-0017-7.

50. Miller SP, Mayer EE, Clyman RI, Glidden DV, Hamrick SE, Barkovich AJ. Prolonged indomethacin exposure is associated with decreased white matter injury detected with magnetic resonance imaging in 
premature newborns at 24 to 28 weeks' gestation at birth. Pediatrics. 2006;117:1626-31, doi: 10.1542/peds.2005-1767.

51. Madan JC, Kendrick D, Hagadorn JI, Frantz ID3rd. National Institute of Child Health and Human Development Neonatal Research Network. Patent ductus arteriosus therapy: impact on neonatal and 18-month outcome. Pediatrics. 2009;123:674-81, doi: 10.1542/peds.2007-2781.

52. Carmo KB, Evans N, Paradisis M. Duration of indomethacin treatment of the preterm patent ductus arteriosus as directed by echocardiography. J Pediatr. 2009;155:819-822.e1, doi: 10.1016/j.jpeds.2009.06.013.

53. Yoshimoto S, Sakai H, Ueda M, Yoshikata M, Mizobuchi M, Nakao H. Prophylactic indomethacin in extremely premature infants between 23 and 24 weeks gestation. Pediatr Int. 2010;52:374-7, doi: 10.1111/j.1442200X.2009.02977.x.

54. Kumar Nair PA, Pai MG, Gazal HA, Da Costa DE, Al Khusaiby SM. Indomethacin prophylaxis for intraventricular hemorrhage in very low birth weight babies. Indian Pediatr. 2004;41:551-8.

55. Boo NY, Mohd-Amin I, Bilkis AA, Yong-Junina F. Predictors of failed closure of patent ductus arteriosus with indomethacin. Singapore Med J. 2006;47:763-8.

56. Clyman RI, Ballard PL, Sniderman S, Ballard RA, Roth R, Heymann MA,et al. Prenatal administration of betamethasone for prevention of patient ductus arteriosus. J Pediatr. 1981;98:123-6, doi: 10.1016/S00223476(81)80557-4.

57. Bose CL, Laughon ML. Treatment to prevent patency of the ductus arteriosus: Beneficial or harmful? J Pediatr. 2006;148:713-4, doi: 10. 1016/j.jpeds.2006.03.015.

58. Zaffanello M, Brugnara M, Bruno C, Franchi B, Talamini G, Guidi G, et al. Renal function and volume of infants born with a very low birthweight: a preliminary cross-sectional study. Acta Paediatr. 2010;99:1192-8, doi: 10.1111/j.1651-2227.2010.01799.x.

59. Evans N. Management of the patent ductus arteriosus in the preterm infant. Paediatrics and Child Health. 2011; 6:247-53, doi: 10.1016/j.paed. 2010.12.003.

60. Varvarigou A, Bardin LC, Beharry K, Chemtob S, Papageorgiu A, Aranda JV. Early ibuprofen administration to patent ductus arteriosus in premature newborn infants. JAMA. 1996;275:539-44, doi: 10.1001/ jama.275.7.539.

61. Van Overmeire B, Follens I, Hartmann S, Creten WL, Van Acker KJ. Treatment of patent ductus arteriosus with ibuprofen. Archives of Disease in Childhood. Fetal and Neonatal Edition. 1997;76:F179-84, doi: 10.1136/fn.76.3.F179.

62. Mosca F, Bray M, Lattanzio M, Fumagalli M, Toscetto C. Comparative evaluation of the effect of indomethacin and ibuprofen on cerebral perfusion and oxygenation in preterm infants with patent ductus arteriosus. Journal of Pediatrics. 1997;131:549-54, doi: 10.1016/S00223476(97)70060-X

63. Speziale MV, Allen RG, Henderson CR, Barrington KJ, Finer NN. Effects of ibuprofen and indomethacin on the regional circulation in newborn piglets. Biology of the Neonate. 1999;76:242-52, doi: 10.1159/ 000014165

64. Pezzati M, Vangi V, Biagiotti R, Bertini G, Cianciulli D, Rubaltelli FF. Effects of indomethacin and ibuprofen on mesentric and renal blood flow in preterm infants with patent ductus arteriosus. J Pediatr. 1999;135:733-8, doi: 10.1016/S0022-3476(99)70093-4.

65. Van Overmeire B, Allegaert K, Casaer A, Debauche C, Decaluwé W, Jespers A, et al. Prophylactic ibuprofen in premature infants: a multicentre, randomised, double-blind, placebo-controlled trial. Lancet. 2004;364:1945-9, doi: 10.1016/S0140-6736(04)17477-1.

66. Shah SS, Ohlsson A. Ibuprofen for the prevention of patent ductus arteriosus in preterm and/or low birth weight infants. Cochrane Database Syst Rev. 2006;1:CD004213.

67. Gournay V, Savagner C, Thiriez G, Kuster A, Roze JC. Pulmonary hypertension after ibuprofen prophylaxis in very preterm infants. Lancet. 2002;359:1486-8, doi: 10.1016/S0140-6736(02)08424-6.

68. Gournay V, Roze JC, Kuster A, et al. Prophylactic ibuprofen versus placebo in very premature infants: a randomised, doubleblind, placebocontrolled trial. Lancet. 2004;364:1939-44, doi: 10.1016/S01406736(04)17476-X

69. Mosca F, Bray M, Stucchi I, Fumagalli M. Pulmonary hypertension after ibuprofen prophylaxis in very preterm infants. Lancet. 2002;360:1023-4, doi: 10.1016/S0140-6736(02)11109-3.

70. Loeliger M, Shields A, McCurnin D, Clyman RI, Yoder B, Inder TE, et al. Ibuprofen treatment for closure of patent ductus arteriosus is not associated with increased risk of neuropathology. Pediatr Res. 2010;68:298-302, doi: 10.1203/PDR.0b013e3181ed1864.

71. Linder N, Bello R, Hernandez A, Rosen C, Birk E, Sirota L, et al. Treatment of patent ductus arteriosus: indomethacin or ibuprofen? Am J Perinatol. 2010;27:399-404, doi: 10.1055/s-0029-1243315.

72. Giniger RP, Buffat C, Millet V, Simeoni U. Renal effects of ibuprofen for the treatment of patent ductus arteriosus in premature infants. J Matern Fetal Neonatal Med. 2007;20:275-83, doi: 10.1080/14767050701227950.

73. Hasan J, Beharry KD, Gharraee Z, Stavitsky Y, Abad-Santos P, AbadSantos M, et al. Early postnatal ibuprofen and indomethacin effects in suckling and weanling rat kidneys. Prostaglandins Other Lipid Mediat. 2008;85:81-8, doi: 10.1016/j.prostaglandins.2007.10.006.

74. Erdeve O, Sarici SU, Sari E, Gok F. Oral-ibuprofen-induced acute renal failure in a preterm infant. Pediatr Nephrol. 2008;23:1565-7, doi: 10. 1007/s00467-008-0835-9.

75. Antonucci R, Cuzzolin L, Arceri A, Fanos V. Urinary prostaglandin E2 in the newborn and infant. Prostaglandins Other Lipid Mediat. 2007;84:1-13, doi: 10.1016/j.prostaglandins.2007.04.006.

76. Antonucci R, Cuzzolin L, Arceri A, Dessì A, Fanos V. Changes in urinary PGE2 after ibuprofen treatment in preterm infants with patent ductus arteriosus. EurJ Clin Pharmacol. 2009;65:223-230, doi: 10.1007/ s00228-008-0586-3.

77. Fanos V, Benini D, Verlato G, Errico G, Cuzzolin L. Efficacy and renal tolerability of ibuprofen vs. indomethacin in preterm infants with patent ductus arteriosus. Fundam Clin Pharmacol. 2005;19:187-193, doi: 10.1111/j.1472-8206.2004.00314.x.

78. Fanos V, Cuzzolin L, Causes and manifestation of nephrotoxicity. In: Shaefer F, Geary F. Clinical Pediatric Nephrology. Mosby Elsevier: Philadelphia 2008

79. Cuzzolin L, Dal Cere M, Fanos V. NSAID-induced nephrotoxicity from the fetus to the child. Drug Saf. 2001;24:9-18, doi: 10.2165/00002018200124010-00002.

80. Cataldi L, Leone R, Moretti U, et al. Potential risk factors for the development of acute renal failure in preterm newborn infants: a casecontrol study. Arch Dis Child Fetal Neonatal Ed. 2005;90:F514-9.

81. Longini M, Perrone S, Vezzosi P, Proietti F, Marzocchi B, Buonocore G, et al. Isoprostane levels in urine of preterm newborns treated with ibuprofen for patent ductus arteriosus closure. Pediatr Nephrol. 2011;26:105-9, doi: 10.1007/s00467-010-1651-6.

82. Vieux R, Desandes R, Boubred F, Semama D, Guillemin F, Buchweiller $\mathrm{MC}$, et al. Ibuprofen in very preterm infants impairs renal function for the first month of life. Pediatr Nephrol. 2010;25:267-74, doi: 10.1007/ s00467-009-1349-9.

83. Vieux R, Zelenina M, Aperia A, Hascoët JM. The renal adverse effects of ibuprofen are not mediated by AQP2 water channels. Pediatr Nephrol. 2010;25:1277-84, doi: 10.1007/s00467-010-1487-0.

84. Ojala R, Ala-Houhala M, Ahonen S, Harmoinen A, Turjanmaa V, Ikonen S, et al. Renal follow up of premature infants with and without perinatal indomethacin exposure. Arch Dis Child Fetal Neonatal Ed. 2001;84:F28-33.

85. Li Y, Zelenina M, Plat-Willson G, Marcoux MO, Aperia A, Casper C. Urinary aquaporin-2 excretion during ibuprofen or indomethacin treatment in preterm infants with patent ductus arteriosus. Acta Paediatr. 2011;100:59-66, doi: 10.1111/j.1651-2227.2010.01943.x.

86. Cassady G, Crouse DT, Kirklin JW, Strange MJ, Joiner CH, Godoy G, et al. A randomized, controlled trial of very early prophylactic ligation of the ductus arteriosus in babies who weighed $1000 \mathrm{~g}$ or less at birth. New England Journal of Medicine. 1989;320:1511-6, doi: 10.1056/ NEJM198906083202302.

87. Mosalli R, Paes B. Ductus Arteriosus: Optimal Fluid Requirements in Preterm Infants NeoReviews. 2010;11:495-502.

88. Clyman R, Cassady G, Kirklin JK, Collins M, Philips JB3rd. The role of patent ductus arteriosus ligation in bronchopulmonary dysplasia: reexamining a randomized controlled trial. J Pediatr. 2009;154:873-6, doi: 10.1016/j.jpeds.2009.01.005.

89. Waleh N, McCurnin DC, Yoder BA, Shaul PW, Clyman RI. Paten ductus arteriosus ligation alters pulmonary gene expression in preterm baboons. Pediatr Res. 2011;69:212-6.

90. Kabra NS, Schmidt B, Roberts RS et al. Neurosensory impairment after surgical closure of patent ductus arteriosus in extremely low birth weight infants. Results from the Trial of Indomethacin Prophylaxis in Preterms. J Pediatr. 2007;150:229-34, doi: 10.1016/j.jpeds.2006.11.039.

91. Chorne N, Leonard C, Piecuch R, Clyman RI. Patent ductus arteriosus and its treatment as risk factors for neonatal and neurodevelopmental morbidity. Pediatrics. 2007;119:165-74, doi: 10.1542/peds.2006-3124.

92. Victorian Infant Collaborative Study Group. Surgery and the tiny baby: sensorineural outcome at 5 years of age. J Paediatr Child Health 1996;32:167-72, doi: 10.1111/j.1440-1754.1996.tb00916.x.

93. Bratlid D, Farstad T. Treatment of a patent ductus arteriosus in premature infants. Tidsskr Nor Legeforen (The Journal of the Norwegian Medical Association). 2009;129:1455-8, doi: 10.4045/ tidsskr.09.31363.

94. Mandhan P, Brown S, Kukkady A, Samarakkody U. Surgical closure of patent ductus arteriosus in preterm low birth weight infants. Congenit Heart Dis. 2009;4:34-37, doi: 10.1111/j.1747-0803.2008.00241.x

95. Malviya M, Ohlsson A, Shah S. Surgical versus medical treatment with cyclooxygenase inhibitors for symptomatic patent ductus arteriosus in preterm infants. Cochrane Database Syst Rev. 2008;23:CD003951.

96. Spanos WC, Brookes JT, Smith MC, Burkhart HM, Bell EF, Smith RJ Unilateral vocal fold paralysis in premature infants after ligation of patent ductus arteriosus: vascular clip versus suture ligature. Ann Otol Rhinol Laryngol. 2009;118:750-3. 
97. Moin F, Kennedy KA, Moya FR. Risk factors predicting vasopressor use after patent ductus arteriosus ligation. Am J Perinatol. 2003;20:313-20, doi: 10.1055/s-2003-42693.

98. Seghaye MC, Grabitz R, Alzen G, Trommer F, Hörnchen H, Messmer BJ,et al. Thoracic sequelae after surgical closure of the patent ductus arteriosus in premature infants. Acta Paediatr. 1997;86:213-6, doi: 10. 1111/j.1651-2227.1997.tb08871.x.

99. McNamara PJ, Stewart L, Shivananda SP, Stephens D, Sehgal A. Patent ductus arteriosus ligation is associated with impaired left ventricular systolic performance in premature infants weighing less than $1000 \mathrm{~g}$. J Thorac Cardiovasc Surg. 2010;140(1):150-7. Erratum in: J Thorac Cardiovasc Surg. 2010 Oct;140:944, doi: 10.1016/j.jtcvs.2010.01.011

100. Cristel M, Sørensen, Jesper N. Steensberg, Greisen G. Surgical ligation of patent ductus arteriosus in premature infants. Dan Med Bul 2010;57:A4160.

101. Mosalli R, AlFaleh K, Paes B. Role of prophylactic surgical ligation of patent ductus arteriosus in extremely low birth weight infants: Systematic review and implications for clinical practice. Ann Ped Cardiol. 2009;2:120-6, doi: 10.4103/0974-2069.58313.

102. Mosalli R, Alfaleh K. Prophylactic surgical ligation of patent ductus arteriosus for prevention of mortality and morbidity in extremely low birth weight infants. Cochrane Database Syst Rev. 2008;(1):CD006181.

103. Bökenkamp R, DeRuiter MC, van Munsteren C, Gittenberger-de Groot AC. Insights into the pathogenesis and genetic background of patency of the ductus arteriosus. Neonatology. 2010;98:6-17, doi: 10.1159/ 000262481

104. Bhandari V, Zhou G, Bizzarro MJ, Buhimschi C, Hussain N, Gruen JR, Zhang H. Genetic contribution to patent ductus arteriosus in the premature newborn. Pediatrics. 2009;123:669-73, doi: 10.1542/peds. 2008-1117.

105. Derzbach L, Treszl A, Balogh A, Vasarhelyi B, Tulassay T, Rigo JJ. Gender dependent association between perinatal morbidity and estrogen receptor-alpha Pvull polymorphism. J Perinat Med. 2005;33:461-2, doi: 10.1515/JPM.2005.082.

106. Bokodi G, Derzbach L, Banyasz I, Tulassay T, Vasarhelyi B. Association of interferon gamma T_874A and interleukin 12 p40 promoter CTCTAA/GC polymorphism with the need for respiratory support and perinatal complications in low birthweight neonates. Arch Dis Child Fetal Neonatal Ed. 2007;92:F25-F29, doi: 10.1136/adc.2005. 086421.

107. Dagle JM, Lepp NT, Cooper ME, Schaa KL, Kelsey KJ, Orr KL, et al. Determination of genetic predisposition to patent ductus arteriosus in preterm infants. Pediatrics. 2009;123:1116-23, doi: 10.1542/peds.20080313.

108. Ma JD, Nafziger AN, Bertino JS Jr. Genetic polymorphisms of cytochrome P450 enzymes and the effect on interindividual, pharmacokinetic variability in extensive metabolizers. J Clin Pharmacol. 2004;44:447-56, doi: 10.1177/0091270004264642.

109. Durrmeyer X, Hovhannisyan S, Médard Y, Jacqz-Aigrain E, Decobert F, Barre J, Alberti C, Aujard Y, Danan C, Baud O. Are cytochrome P450 CYP2C8 and CYP2C9 polymorphisms associated with ibuprofen response in very preterm infants? PLoS One. 2010;5:e12329, doi: 10. 1371 /journal.pone.0012329.

110. Waleh N, Hodnick R, Jhaveri N, McConaghy S, Dagle J, Seidner S, et al. Patterns of gene expression in the ductus arteriosus are related to environmental and genetic risk factors for persistent ductus patency. Pediatr Res. 2010;68:292-7, doi: 10.1203/PDR.0b013e3181ed8609.

111. Fanos V, Yurdakök M. Personalized neonatal medicine. J Matern Fetal Neonatal Med. 2010;23(Suppl 3):4-6, doi: 10.3109/14767058.2010.513103.

112. Atzori L, Antonucci R, Barberini L, Griffin JL, Fanos V. Metabolomics: a new tool for the neonatologist. J Mat Fetal Neonatal Med. 2009;22:50-53, doi: 10.1080/14767050903181500.

113. Atzori L, Antonucci R, Barberini L, Locci E, Marincola FC, Scano P, et al. $1 \mathrm{H}$ NMR-based metabolomic analysis of urine from preterm and term neonates. Front Biosci (Elite Ed). 2011;3:1005-12.

114. Gien J. Controversies in the management of patent ductus arteriosus. NeoReviews. 2008;9:e477-e482, doi: 10.1542/neo.9-10-e477

115. Laughon M, Bose C, Benitz WE. Patent ductus arteriosus management: what are the next steps? J Pediatr. 2010;157(3):355-7.

116. Noori S. Patent ductus arteriosus in the preterm infant: to treat or not to treat. J Perinat 2010;30S:S31-S3, doi: 10.1038/jp.2010.97.

117. Jones LJ, Craven PD, Attia J, Thakkinstian A, Wright I. Network metaanalysis of indomethacin versus ibuprofen versus placebo for PDA in preterm infants. Arch Dis Child Fetal Neonatal Ed. 2011;96:F45-52, doi: 10.1136/adc.2009.168682.

118. Sweet DG, Carnielli V, Greisen G, Hallman M, Ozek E, Plavka R, et al. European Association of Perinatal Medicine. European consensus guidelines on the management of neonatal respiratory distress syndrome in preterm infants - 2010 update. Neonatology. 2010;97:40217, doi: $10.1159 / 000297773$

119. Antonucci R, Bassareo P, Zaffanello M, Pusceddu M, Fanos V. Patent ductus arteriosus in the preterm infant: new insights into pathogenesis and clinical management. J Matern Fetal Neonatal Med. 2010;23(Suppl 3):34-7, doi: 10.3109/14767058.2010.509920.

120. Alfaleh K. Indomethacin prophylaxis revisited: changing practice and supportive evidence. Acta Paediatrica. 2011;100:641-6, doi: 10.1111/j. 1651-2227.2011.02189.x.

121. Sekar KC, Corff KE. Treatment of patent ductus arteriosus: indomethacin or ibuprofen? J Perinatol. 2008;28(Suppl 1):S60-2, doi: 10.1038/jp. 2008.52.

122. Chiruvolu A, Jaleel MA. Therapeutic management of patent ductus arteriosus. Early Hum Dev. 2009;85:151-5, doi: 10.1016/j.earlhumdev. 2008.12.007. 